\title{
BMJ
}

\section{Implementation and adoption of nationwide electronic health records in secondary care in England: qualitative analysis of interim results from a prospective national evaluation}

\author{
Ann Robertson ${ }^{1}$ Kathrin Cresswell ${ }^{1}$ Amirhossein Takian ${ }^{2}$ Dimitra Petrakaki ${ }^{3}$ Sarah Crowe ${ }^{4}$ Tony Cornford ${ }^{3}$ \\ Nicholas Barber ${ }^{2}$ Anthony Avery ${ }^{4}$ Bernard Fernando ${ }^{1}$ Ann Jacklin ${ }^{5}$ Robin Prescott ${ }^{1}$ Ela Klecun ${ }^{3}$ James Paton $^{6}$ \\ Valentina Lichtner ${ }^{3}$ Casey Quinn ${ }^{4}$ Maryam Ali ${ }^{3}$ Zoe Morrison ${ }^{1}$ Yogini Jani ${ }^{2}$ Justin Waring ${ }^{4}$ Kate Marsden ${ }^{4}$ Aziz \\ Sheikh ${ }^{1}$
}

${ }^{1}$ eHealth Research Group, Centre for Population Health Sciences, University of Edinburgh, Edinburgh EH8 9AG

${ }^{2}$ Department of Practice and Policy, School of Pharmacy, University of London, London

${ }^{3}$ Department of Management, London School of Economics and Political Science, London

${ }^{4}$ Division of Primary Care, University of Nottingham, Nottingham

${ }^{5}$ Imperial College Healthcare N HS Trust, London

${ }^{6}$ Burton Hospitals NHS

Foundation Trust, Burton upon

Trent

Correspondence to: A Sheikh, professor of primary care research and development,

aziz.sheikh@ed.ac.uk

Cite this as: $B M J$ 2010;341:C4564 doi:10.1136/bmj.c4564

\section{ABSTRACT}

Objectives To describe and evaluate the implementation and adoption of detailed electronic health records in secondary care in England and thereby provide early feedback for the ongoing local and national rollout of the NHS Care Records Service.

Design A mixed methods, longitudinal, multisite, sociotechnical case study.

Setting Five NHS acute hospital and mental health trusts that have been the focus of early implementation efforts and at which interim data collection and analysis are complete.

Data sources and analysis Dataset for the evaluation consists of semi-structured interviews, documents and field notes, observations, and quantitative data. Qualitative data were analysed thematically with a sociotechnical coding matrix, combined with additional themes that emerged from the data.

Main results Hospital electronic health record applications are being developed and implemented far more slowly than was originally envisioned; the topdown, standardised approach has needed to evolve to admit more variation and greater local choice, which hospital trusts want in order to support local activity. Despite considerable delays and frustrations, support for electronic health records remains strong, including from NHS clinicians. Political and financial factors are now perceived to threaten nationwide implementation of electronic health records. Interviewees identified a range of consequences of long term, centrally negotiated contracts to deliver the NHS Care Records Service in secondary care, particularly as NHS trusts themselves are not party to these contracts. These include convoluted communication channels between different stakeholders, unrealistic deployment timelines, delays, and applications that could not quickly respond to changing national and local NHS priorities. Our data suggest support for a "middle-out" approach to implementing hospital electronic health records, combining government direction with increased local autonomy, and for restricting detailed electronic health record sharing to local health communities.

Conclusions Experiences from the early implementation sites, which have received considerable attention, financial investment and support, indicate that delivering improved healthcare through nationwide electronic health records will be a long, complex, and iterative process requiring flexibility and local adaptability both with respect to the systems and the implementation strategy. The more tailored, responsive approach that is emerging is becoming better aligned with NHS organisations' perceived needs and is, if pursued, likely to deliver clinically useful electronic health record systems.

\section{INTRODUCTION}

Electronic health records are being introduced in Europe, North America, Australasia, the Middle East, and elsewhere. ${ }^{12}$ There is no universally accepted definition of the term electronic health record, but we use it to mean a digital, longitudinal record of a patient's health and health care that can be shared by different healthcare providers. ${ }^{3}$ Although electronic health records are widely viewed as central to modernising the organisation and delivery of sustainable, high quality health care, the uptake of such records in hospital has tended to be slow. ${ }^{4}$ Approaches to deployment of electronic health records vary from home grown systems in single organisations with the necessary technical and managerial capacity; to interoperability standards for linking multiple information technology (IT) systems; to top-down, government driven, national implementations of standardised, commercial software applications. The last approach was chosen in England in 2002: the nationwide implementation of electronic health records, known as the National Health Service (NHS) Care Records Service, is the cornerstone of the $£ 12.7 \mathrm{bn}$ National Programme for IT. ${ }^{56}$ 
A limited range of standardised applications was to be centrally procured and implemented in, initially, five geographical clusters by centrally contracted local service providers; these new systems were then planned to connect to a national database and messaging service (the NHS Spine). The resulting NHS Care Records Service is thus in two parts ${ }^{7}$ a centrally stored summary care record containing basic clinical information for emergencies (which has been separately evaluated ${ }^{89}$ ) and a locally held and shared detailed electronic health record. The latter, detailed electronic health record is the focus of this paper.

The stated anticipated benefits of the National Programme for IT are summarised in appendix 1 (on bmj.com). Previous research into the programme's progress in hospital trusts reported findings from 25 interviews with senior NHS staff from four acute trusts. ${ }^{10}$ Those interviewees were unanimously and "unreservedly" supportive of the programme's goals, but they highlighted several concerns, including delayed deployments, local financial deficits, and poor communication between local managers and the agency responsible for the programme. Our research builds on and expands this earlier work by investigating the NHS Care Records Service in diverse secondary care settings and by interviewing a more comprehensive range of NHS trust staff.

We were commissioned to undertake an independent evaluation of early experiences of implementing the NHS Care Record Service in English hospitals to inform the subsequent rollout of nationwide electronic health records. This is, we believe, the largest contemporaneous and longitudinal evaluation of an electronic health record's implementation ever undertaken. Here, we report interim findings from five "early adopter" secondary care trusts that have been the focus of national implementation efforts and where the first rounds of collection and analysis of evaluation data are complete. Our primary objectives are to identify insights and experiences that can usefully shape the future direction of the NHS Care Records Service in hospitals at a critical juncture (triggered by a change in government and recently announced austerity measures, and plans to restructure the NHS). ${ }^{11}$ Secondly, publishing early results from England's experiences of implementing an ambitious and expensive IT enabled transformation of healthcare services may offer lessons for other countries that are embarking on large scale, nationwide electronic health record programmes. ${ }^{12}$

\section{METHODS \\ Design}

We are undertaking a mixed methods, longitudinal, ${ }^{12}$ socio-technical, ${ }^{13}$ multisite case study evaluation (see appendix 2 on bmj.com). Data collection is due to end in 2011. The evaluation protocol (appendix 3 on bmj.com) was aligned to the deployment schedule for the NHS Care Records Service and envisaged a traditional before-and-after evaluation design. The design was adapted in response to deployment delays and the diversity of processes for introducing the new systems in England's hospitals, but the evaluation's original aims of informing local and national rollout of electronic health records have been retained. The adapted approach treats each participating organisation as an individual case study of the socio-technical processes of implementing - and, where sufficient progress has been made, adopting - newly introduced IT systems for the NHS Care Records Service. While each case study site is evaluated as a distinct enactment of the NHS Care Records Service, reviewing findings from our multiple case studies allows important common themes to be identified.

\section{Governance and ethics}

The research was classed as a service evaluation by the NHS Research Ethics Committee (reference 08/H0703/ 112). The lead institution is compiling and maintaining a record of all data collection activity as the multidisciplinary collaborative team continues to generate a large longitudinal dataset. Prior informed consent to join the evaluation was obtained from participating NHS trusts, and researchers complied with local requirements for approvals on a case by case basis. Informed consent was also obtained from participating individuals. We have protected participants' anonymity and, as far as possible, the anonymity of participating sites by removing identifying information from the data.

\section{Sampling}

We used purposive sampling ${ }^{14}$ to identify 12 diverse trusts across the areas where the National Programme for IT is currently being implemented (London; North, Midlands and East; and Southern England) and to include sites implementing all three centrally procured hospital applications (Lorenzo and Cerner Millennium for acute hospitals and $\mathrm{RiO}$ for mental health). Purposive sampling was guided by the research aims - to study NHS hospital trusts in the process of implementing one of Cerner Millennium, Lorenzo, or $\mathrm{RiO}$ and, within the limited deployments to date, to recruit organisations with a varied range of geographical settings and local deployment strategies. Hence, purposive sampling was not designed to generate a representative sample of all secondary care NHS trusts in England (this would have been inappropriate as most trusts are not yet implementing the NHS Care Records Service). Rather, we sought to recruit as varied as possible a sample of early adopter sites from which the breadth and, more importantly, the depth of inquiry could generate potentially transferable lessons. ${ }^{15-17}$

No invited NHS trust refused to participate in the evaluation. We decided not to pursue evaluation work at one trust where there were access difficulties after initial recruitment. Lack of engagement, which would severely compromise data collection, seemed to be the result of competing priorities for trust staff at a time of organisational change.

Within each of the remaining case studies, purposive sampling aimed to recruit a diverse range of interviewees with a stake in implementation of the NHS Care Records Service, actively seeking different 
perspectives, including outlier views. Trust interviewees in the five case studies reported here were hospital managers, members of the implementation team and IT staff, doctors, nurses, allied health professionals, administrative staff, and, where appropriate, patients and carers (table 1). In addition, we purposively sampled knowledgeable individuals who were not NHS trust staff and who offered additional perspectives on implementing the NHS Care Records Service. Interviewees came from NHS Connecting For Health (part of the Department of Health Informatics Directorate and responsible for overseeing the National Programme for IT), strategic health authorities (the regional NHS management organisations responsible for local delivery of the programme), local service providers (contracted to deploy the NHS Care Records Service in secondary care), and the commercial companies subcontracted to supply the applications.

\section{Settings}

The reported research is set in five diverse secondary care NHS hospital trusts in England. These include one site implementing Cerner Millennium and one site implementing $\mathrm{RiO}$, for which British Telecommunications is the local service provider contracted to deliver
London services, and three sites implementing Lorenzo in the North, Midlands and East region, where the local service provider is Computer Science Corporation (figure). Anonymised information about the trusts is given in table 1 .

\section{Data collection}

Qualitative data collected at each case study site consisted of trust documents, transcripts of semi-structured interviews (conducted face-to-face, by telephone, and by email), and on-site observations and accompanying field notes (table 1). We also reviewed specialist IT publications, national media reports, and publications by parliamentary and professional bodies to track the wider context (macro-environment) in which implementations took place.

We collected public NHS trust documents and, with permission, private ones. Documents collected from the trusts were copies of the trusts' organisational structure, deployment timelines for the NHS Care Records Service, project initiation documents, business cases, risk registers, minutes from board meetings related to the NHS Care Records Service, "lessons learned" documents, training strategy documents, and annual reports. Additional relevant local documents, such as

Table 1|Characteristics of the five NHS acute hospital and mental health trusts implementing NHS Care Records Service applications for which interim data collection and analysis are complete

$\begin{array}{ll}\begin{array}{l}\text { Case study identifier and } \\ \text { description }\end{array} & \begin{array}{l}\text { Application, supplier, } \\ \text { local service provider }\end{array} \\ \begin{array}{l}\text { Site A: acute NHS hospital trust, } \\ \text { London area (urban) }\end{array} & \begin{array}{l}\text { Cerner Millennium, } \\ \text { Cerner, BT }\end{array}\end{array}$

London area (urban)

\section{Application's deployment status and plans}

Due to deploy clinical functionality (such as test requests and 26 interviews: 17 trust staff ( 3 IT, 5 implementation team, 7 results) in May 2010; patient administration system in 2011; clinical, 2 administrative); 5 patients or carers; 2 strategic plans to build on clinical functionality over 5 years. Trust-wide health authority staff (LPfIT); 2 local service provider staff. deployment

\section{Attendance at trust's NHS Care Records Service board}

$\begin{array}{ll}\text { Site B: NHS foundation trust, North, } & \text { Lorenzo (release 1), } \\ \text { Midlands and East area } & \text { iSoft, CSC }\end{array}$ (predominantly rural)
Small scale implementation as an order communication system (ordering requests and results); plans to deploy release 1.9 patient administration system trust-wide meetings. Trust documents; public body and press reports; field notes. All but 4 interviews audio recorded and transcribed ( 2 patients and 2 healthcare staff declined to be recorded, and interviewer took contemporaneous notes). Data collection March-October 2009

45 interviews: 35 trust staff (13 implementation team, 18 clinical, 4 administrative); 6 patients; 2 local service provider staff; 2 NHS Connecting for Health staff. Trust documents; press reports; field notes. All but 2 interviews audio recorded and transcribed (1 nurse declined to be recorded and in 1 interview the recorder failed, and interviewer took contemporaneous notes). Data collection February-October 2009
Site C: NHS foundation trust, North, Lorenzo (release 1), Midlands and East area (mixed urban iSoft, CSC and surrounding communities)

Small scale implementation in one department as an order communication system (ordering requests and results); due to digitalise requesting and reporting processes and make some related clinical processes "paper-light"; due to deploy clinical documentation project department-wide. Plans to have, in effect, three go-lives in one project

Site H: NHS foundation trust, North, Lorenzo (release 1), Midlands and East area (urban) iSoft, CSC

Small scale implementation of clinical documentation functionality. Plans to roll out functionality to other specialties before considering trust-wide roll out

Site M: NHS foundation trust and integrated mental health and soci care trust, London area (urban)
RiO (5.1), CSE Healthcare Trust-wide deployment completed in mid-2009, except for Systems, BT prescription, which it is planned to deploy mid-2010
6 interviews with trust staff ( 4 implementation team, 2 clinical). Trust documents; field notes. Interviews audio recorded and transcribed. Data collection June 2009

13 interviews with trust staff ( 6 implementation team, 7 clinical). Trust documents; press reports; field notes. Interviews audio recorded and transcribed. Data collection July 2009 to February 2010

24 interviews: 20 trust staff (10 implementation team, 10 clinical); 3 LPfIT staff; 1 local service provider staff). Attendance at Trust's NHS Care Records Service board meetings. Trust documents; public body and press reports; on site observations; field notes. All interviews audio recorded and transcribed except 1 (at interviewee's request, contemporaneous interviewer notes) and 1 email interview (at interviewee's request). Data collection MayNovember 2009 


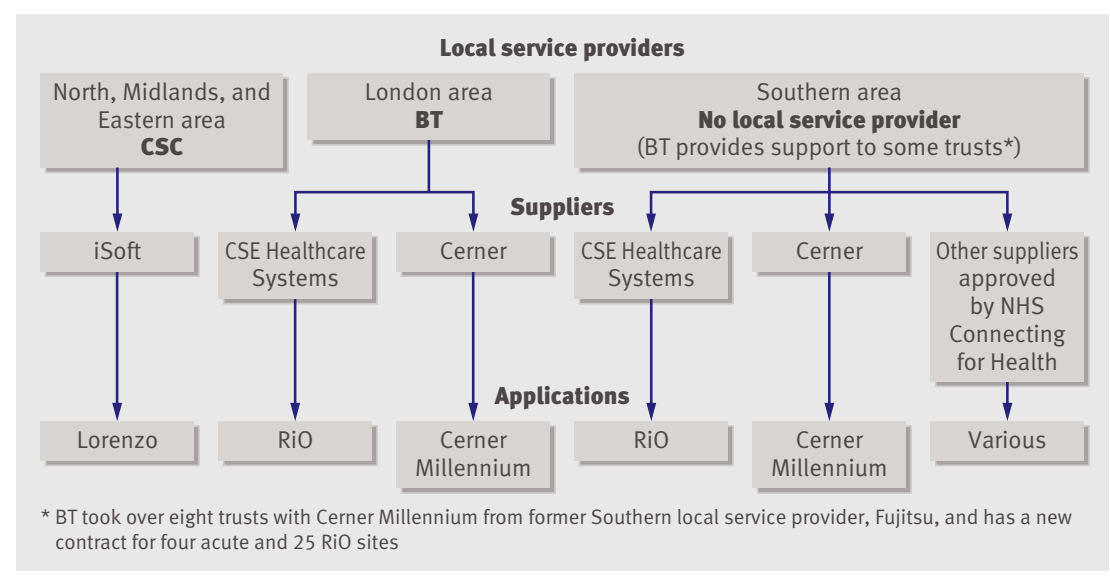

The NHS Care Records Service in secondary care in 2010: local service providers, local service provider suppliers, and NHS Care Records Service applications.

work process maps, were collected where these were accessible. Trust documents provided the local context for each case study and complemented other data sources by, for example, allowing comparison of their contents with national policy statements and with data gathered in interviews with trust staff.

Interviews, lasting on average an hour, explored individuals' expectations, experiences, and opinions of electronic health records. The interviewers were five university employees (KC, AT, DP, SC, and $\mathrm{AR}$ ), all experienced qualitative researchers with no prior relationships with the interviewees. Early interviews were guided by topic guides (see appendix 4) designed for specific interviewee groups. As each case study progressed, the lead researcher at that site adapted interview guides and other data collection to respond to previously collected data and emerging themes. Nearly all interviews were audio-recorded (table 1). For a few interviews, participants requested not to be recorded, and in such instances the researcher took notes. Professional transcribers transcribed the interviews verbatim, with the interviewers then checking the transcripts for accuracy. Copies of the transcripts were available to interviewees, although only a minority requested to see them; there were no cases of interviewees disputing the transcript contents.

Data collection finished at each of the study sites when the research team judged that saturation had been achieved - that is, when no new, rich, diverse data relevant to the evaluation were being acquired. This was partly influenced by factors related to the setting - such as the scale of the deployment at the site (for example, limited to a ward or hospital-wide) and type of functionalities being introduced (for example, ordering of tests or clinical notes). The individual data collection periods varied by site (table 1); all of the data reported here were collected between February 2009 and February 2010. We will revisit each site to collect longitudinal data in order to understand how implementation progresses.

\section{Data analysis}

Qualitative data collection and analysis were iterative. Researchers combined top-down, thematic coding that was guided by a matrix of socio-technical factors ${ }^{13}$ and bottom-up, inductive coding that allowed themes to emerge from the data without prior theoretical categorisation. ${ }^{15-17}$ From a socio-technical perspective, organisational and human (socio) factors and IT system factors (technical) are interrelated parts of one system, each shaping the other. ${ }^{18}$ Information about the socio-technical approach that provides the theoretical underpinning for the evaluation is given in appendix 5 on bmj.com.

The software package NVivo 8 was used to manage interviews, field notes, and documentary data. Data coding was undertaken by the researchers who collected the data. In keeping with an interpretative qualitative approach, which recognises the subjectivity of the researcher, ${ }^{1617}$ we used a range of approaches to validate data quality and credibility, including checking for face validity, looking for disconfirming evidence, data triangulation by data source, and seeking informant feedback. Emerging findings were shared with participating trusts for feedback. Transcripts, codes, emerging findings, and their interpretations were presented and discussed by research colleagues at each stage of the analysis in regular team meetings and in multidisciplinary data analysis workshops and steering group meetings. Discussions and feedback supported researcher reflexivity and confirmed the interim results' trustworthiness and credibility. ${ }^{19}$

\section{RESULTS}

Several themes echoed those previously reported in the electronic health record implementation literature (see box). ${ }^{20}$ Rather than explore these further, in this paper we focus on themes from the macro-environment and cross-cutting themes that are particularly relevant to English health policy and national and international debates about approaches to implementing electronic health records. The key themes are

- How the envisioned NHS Care Records Service in England has evolved substantially since its launch

- Hospital staff want electronic health records, but the type of electronic health record and scale of data sharing that are wanted are far less clear

- Increasing uncertainties about the future of the current NHS Care Records Service Programme

- Perceived multiple adverse consequences of centrally negotiated contracts to deliver nationwide electronic health records

- Trusts wanting systems that are better tailored to their particular organisation, not standardised systems

- Community level implementations of electronic health records and data sharing may present the optimal way forward.

A selection of supporting data is given to illustrate each theme. 
Main themes from interviews with staff implementing three NHS Care Records Service applications at five case study sites

\author{
Organisational dimension \\ - Organisational context \\ - Getting the organisation ready for change \\ - Infrastructure \\ - Planning \\ - Leadership and management \\ - Trust resources \\ - Teamwork and communication \\ - Learning and evaluation \\ - Sharing lessons learned \\ - Perceived risks and benefits of implementing application \\ - Realistic expectations and timelines \\ Social or human dimension \\ - NHS Care Records Service vision(s) \\ - Needs of stakeholders and perceived benefits \\ - Interactions between stakeholder groups \\ - Attitudes, expectations, concerns, and motivations \\ - Champions \\ - Integration of system with existing work processes \\ - Ownership and resistance \\ - Workarounds \\ - End user input into design \\ - User engagement \\ - Patients' views \\ - IT literacy in NHS \\ - Training to use new application \\ - Support for users \\ - Realistic expectations and timelines \\ Technical dimension \\ - Data cleansing and migration \\ - Features and functionalities of application \\ - Adaptability and flexibility of new system (customisability) \\ - Integration with existing systems \\ - Stability \\ - System benefits \\ - Usability and performance-software \\ - Usability and performance-hardware \\ - Data security and confidentiality \\ - Smartcard log-in \\ - Legitimate relationships and "role based access"
}

The macro-environment: the evolving nature of the NHS Care Records Service

Despite recognised successes in delivering components of the overall programme-for instance, introducing a fast NHS broadband network (N3) and picture archiving and communications systems in all hospitals - the National Programme for IT has struggled to deliver the NHS Care Records Service as originally envisioned in the planned timescale. Consequently, it has attracted negative media coverage and critical questioning by parliamentary bodies charged with scrutinising government spending. Table 2 gives a timeline of programme developments, including some key parliamentary and independent reports published in the course of the programme.

Major adjustments to the NHS Care Records Service include departures of two local service providers, repeatedly re-negotiated central contracts, changes to NHS Connecting for Health's staff and governance structures, delays with software, and adjustments to the delivery model-and, in part as a consequence of these, rollout delays. Further, since 2004, over half of England's NHS trusts have become autonomous NHS organisations (that is, foundation trusts) ${ }^{34}$ and some are now choosing to implement their own choice of electronic health record solutions independently of NHS Connecting for Health.

Hence, the envisioned approach to implementing the NHS Care Records Service in hospitals - delivering standardised applications with phased introductions of integrated clinical functionalities-has changed. It has evolved into various IT systems related to the NHS Care Records Service - such as patient administration systems, tests ordering, pathology reporting, e-prescribing, and maternity systemsbeing implemented differently in different hospital trusts. This is a more service based model of deployment, echoing the "Clinical 5" systems identified in the 2008 Health Informatics Review. ${ }^{28}$ It may also be seen to represent a shift from an electronic health record conceptualised as a database of pooled information to an electronic health record as a system to coordinate diverse transactions between clinicians and various specialist services. Deployments of IT systems related to the NHS Care Records Service to date range from small scale, extended "soft launches" of a local service provider application that is still under development to trust-wide "big bang" deployments of more established applications. The implementation area boundaries for the two local service providers that retained their contracts have become less clear.

\section{Hospitals still want electronic health records-but what} kind?

Concordant with earlier research,${ }^{10}$ our data indicated that electronic health records were still strongly supported by most interviewees despite frequent accounts of multiple frustrations with the programme to deliver the NHS Care Records Service. Many NHS clinicians supported electronic health records. A distinction may be drawn between the enthusiasm clinicians expressed for imagined, ideal electronic health record systems and the more mixed perceptions of those starting to use current NHS Care Records Service applications. Further, clinicians' enthusiasm for electronic health records often related to perceived benefits in their immediate surroundings and did not necessarily relate to the NHS Care Records Service goal of geographically widespread sharing of patient data. 
"I think, ultimately, it's a major win-win; it will be fantastic if it works, and the sooner the better as far as I'm concerned because patients' notes, everything that hangs round patients' notes and appointments, work scheduling, prescribing, ordering tests, is just so clumsy in a paper world." doctor, site B.

"It's actually speeding things up, and it's more reliable about information. It's live information."community nurse, site $\mathrm{M}$.

This support for the concept of electronic health records was often tempered by early experiences of using newly introduced NHS Care Records Service applications.

"I was going into all the right fields quite quickly, but the time it took the computer programme to move through the fields was much greater than the time it took me to input the information, such that it took me at least 20 minutes to do this; and I could have done the paper exercise on the forms we already had, I would think, in 10 or less."consultant, site B.
"I think there will also be some workload implications, because I see people at home, so I'm not going to have access to anything in the patient's home. I'm inevitably going to have to keep some things on paper."- consultant, site M.

The goal of access to patients' electronic health records from other parts of the country was described as an expensive and problematic solution to a nonexistent clinical problem by the single clinician who expressed adamant opposition to the NHS Care Records Service (although he supported the use of healthcare IT generally).

"... apart from our ability as a nation to count, there's no strategic advantage in being able to know the records of somebody in Newcastle in London because there's very little mobility that causes problems for patients."- consultant, site A.

Others, however, highlighted both local and national data sharing as important aspects of electronic health records.

"I think there is a huge amount of benefit for this to be truly developed as a patient care record whereby

\section{Table 2 | Timeline showing some key developments in the NHS National Programme for IT (NPfIT) in England and some key publications}

\begin{tabular}{|c|c|c|}
\hline Date & Developments in NPfIT & Key publications on the NHS or NPfIT \\
\hline 1998 & NHS Executive commits to detailed electronic health records & $\begin{array}{l}\text { NHS Executive. Information for Health: an Information Strategy for the } \\
\text { Modern NHS 1998-2005. }\end{array}$ \\
\hline 2002 & $\begin{array}{l}\text { NPfIT starts } \\
\text { Richard Granger appointed NHS IT director }\end{array}$ & $\begin{array}{l}\text { House of Commons Library. NHS funding and reform: the Wanless Report. } \\
{ }^{22} \\
\text { Department of Health. Delivering 21st Century IT Support for the NHS: } \\
\text { National Strategic Programme. }\end{array}$ \\
\hline 2003 & $\begin{array}{l}\text { BT awarded contract for the national data Spine } \\
\text { Local service provider } 10 \text { year contracts awarded (CSC for North West and West Midland } \\
\text { cluster; BT Capital Care Alliance for London cluster; Fujitsu for Southern cluster; Accenture } \\
\text { for North East and Eastern England clusters) }\end{array}$ & \\
\hline 2004 & BT awarded N3 (NHS broadband network) contract & $\begin{array}{l}\text { Royal Academy of Engineering, British Computer Society. The Challenges of } \\
\text { Complex IT Projects. }{ }^{23}\end{array}$ \\
\hline 2005 & $\begin{array}{l}\text { NHS Connecting for Health (NHS CFH) set up to deliver NPfIT } \\
\text { Contract reset } 1 \text { (BT) for "interim solutions" in London }\end{array}$ & \\
\hline 2006 & $\begin{array}{l}\text { Accenture withdraws as local service provider; CSC awarded } 9 \text { year contract for Accenture's } \\
\text { former clusters }\end{array}$ & $\begin{array}{l}\text { British Computer Society. The Way Forward for NHS Health Informatics. }{ }^{24} \\
\text { National Audit Office. Department of Health: The National Programme for IT in } \\
\text { the NHS. }{ }^{25}\end{array}$ \\
\hline 2007 & $\begin{array}{l}\text { NPfIT Local Ownership Programme (devolves responsibility for local delivery of the } \\
\text { programme from NHS CFH to groupings of strategic health authorities; replaces original five } \\
\text { clusters with three programme areas: Southern (local service provider Fujitsu), London (local } \\
\text { service provider BT) and North, Midlands and East (local service provider CSC) } \\
\text { Contract reset } 2 \text { (BT) for "best of breed" London solutions }\end{array}$ & $\begin{array}{l}\text { House of Commons Committee of Public Accounts. Department of Health: } \\
\text { The National Programme for IT in the NHS. }{ }^{26}\end{array}$ \\
\hline 2008 & $\begin{array}{l}\text { Fujitsu contract for local service provider in Southern area terminated, legal dispute } \\
\text { continues } \\
\text { Contract reset negotiations } 3 \text { (BT) for new delivery model in London } \\
\text { Richard Granger, head of NHS CFH, leaves in January; Gordon Hextall, acting head, leaves in } \\
\text { April; Christine Connelly and Martin Bellamy appointed to jointly lead NHS CFH in September }\end{array}$ & $\begin{array}{l}\text { National Audit Office. The National Programme for IT in the NHS: Progress } \\
\text { since } 2006 .^{5} \\
\text { Department of Health. High quality care for all: NHS Next Stage Review final } \\
\text { report. }{ }^{27} \\
\text { Department of Health. Health Informatics Review: Report. }{ }^{28}\end{array}$ \\
\hline 2009 & $\begin{array}{l}\text { BT awarded additional contract to take over eight trusts formerly with Fujitsu (seven after } \\
\text { merger of two trusts), plus } 25 \text { trusts for RiO and four additional acute trusts in Southern area } \\
\text { Other Southern trusts given choice of local service provider solution from BT or CSC or from } \\
\text { various suppliers in Additional Supply Capability and Capacity List (ASCC) } \\
\text { Martin Bellamy, director of programmes and systems delivery, NHS CFH, resigns } \\
\text { NHS CFH, headed by Christine Connelly, is integrated with Department of Health Informatics } \\
\text { Directorate } \\
\text { November deadline for new deployment of Cerner Millennium across an additional acute } \\
\text { trust in London area (met) } \\
\text { Parliamentary announcement of contract renegotiations with BT and CSC-seeking NPfIT } \\
\text { cost savings }\end{array}$ & $\begin{array}{l}\text { Royal College of General Practitioners. Informing shared clinical care: Final } \\
\text { report of the Shared Record Professional Guidance project. }{ }^{29} \\
\text { Joseph Rowntree Reform Trust. Database State. }{ }^{30} \\
\text { Independent Review of NHS and Social Care IT. }{ }^{31} \text { (commissioned by } \\
\text { Conservative Party) } \\
\text { House of Commons Public Accounts Committee. The National Programme for } \\
\text { IT in the NHS: Progress since 2006. }{ }^{32}\end{array}$ \\
\hline 2010 & $\begin{array}{l}\text { March deadline for deployment of Lorenzo across an acute trust in North, Midlands and East } \\
\text { area (not met) } \\
\text { New memorandum of agreement signed between BT and NHS CFH, including reduced } \\
\text { number of deployments in acute trusts in London; contract discussions with CSC continuing } \\
\text { May: UK general election-new coalition government }\end{array}$ & $\begin{array}{l}\text { Cruickshank J. Fixing NHS IT: A plan of action for a new government. }{ }^{33} \\
\text { Department of Health. Equity and Excellence: Liberating the NHS. }{ }^{11}\end{array}$ \\
\hline
\end{tabular}


all disciplines, everyone who is in contact with the patient, records things in one place."-

implementation manager, site $\mathrm{B}$.

"It would be helpful to have a national system so you would get people that have come down, maybe, from Manchester or Liverpool or wherever because there is the big train station here and people get picked up by the police and brought in and they are disturbed and can't really give a history. It would be really helpful to be able to access notes nationally and not just within an organisation"- doctor, site M.

\section{Uncertainties about the future of the programme are intensifying}

Perceived uncertainties about the programme's future intensified in advance of the UK general election. Respondents repeatedly raised the possibility of radical changes. They referred to statements from political parties in favour of dismantling the programme, to organisational and senior staff changes in the programme, to the history of deployment delays, and to the UK economic recession and related anticipated curbs on NHS spending. Both NHS trust interviewees and local service providers expressed fears that progress in developing the central NHS IT infrastructure and shared detailed electronic health records could be lost, with a considerable waste of public money and effort already expended.

"I have my doubts as to the future. Not least because of the political environment. There is a huge amount of work to get it into an acceptable state, where people will be screaming to come and buy it. If you want to sell something, the best way to sell something is if someone wants to buy it."consultant, site B.

"I'm just wondering how does that work [if a new government scraps the programme] and what a horrendous waste of money that would be, you know, and if there's any way of getting that message home to a few people, because I do realise it is a very political thing, but it would be such a crime, it would really be terrible."-IT manager, site $\mathrm{H}$.

"We're just, um, deeply worried that we'll miss the boat because the plug may be pulled because of other political and financial pressures."-local service provider A, interviewee 2 .

Centrally negotiated contacts and the "ruthless standardisation" described in the Department of Health's 2002 national strategy were designed in part to contain programme costs. ${ }^{6}$ The top-down approach was also in part a response to the perceived history of slow and uneven development of NHS IT systems before the programme. ${ }^{21} \mathrm{~A}$ major perceived risk now was a possible radical swing back to a "bottom-up" approach that would leave responsibility for NHS IT developments with individual trusts and at best aspires to link multiple local systems using interoperability standards. Although a few interviewees perceived benefits in the local choice and sense of ownership that a bottom-up approach would bring, others believed it currently impossible to integrate disparate systems and that attempting to do so would set back electronic health records by many years.

Any detailed electronic health record resulting from a "bottom-up" approach would not be a single, shared electronic health record.

"Standards and interoperability-what does that mean? Where am I going to get my view of the patient? I am never going to be able to see my view of the patient because there's going to be $30 \%$ here, 20 over there, 50 over there. Where's going to hold the $100 \%$ of the data that I need to see my patient?"-local service provider A, interviewee 2.

Some NHS interviewees were determined to carry on with implementing electronic health records, despite deployment delays and programme uncertainties, as both the potential risks and potential benefits of introducing electronic health records had become clearer.

"Now the way in which that gets delivered, I mean at the moment as far as the trust is concerned, this particular organisation will carry on, and I have the full intention of getting something deployed. I will stay until I finish. I'm absolutely determined."implementation team, site A.

Interviewees identify multiple adverse consequences of centrally negotiated contracts

NHS Connecting for Health devolved responsibility for delivering the programme locally to groupings of strategic health authorities in 2007 but retained responsibility for the central contracts. Local service providers have responsibility for their own subcontracts with systems suppliers. The "customers" for the NHS Care Records Service- the hospital trusts-have no direct contractual relation with NHS Connecting for Health, the local service providers, or the suppliers of the NHS Care Records Service applications.

The difficulties arising from this arrangement were evident from NHS interviewees repeatedly speaking of convoluted communication channels and, particularly, frustratingly slow response times to deal with requests for software fixes or changes.

"But what has to happen is it goes to this group to be approved, and then that group to be approved, and it goes all the way round the houses, and then eventually it gets to the developer, and they say, 'Well, it hasn't been scheduled for a build so I can't touch this yet.' So then they've got to schedule it for a build, but they say we're fixed for the next three builds, and they're monthly, so that then brings another three month delay to it all."-IT manager, site $\mathrm{H}$.

"In practice, what it means is that something goes wrong, the IT people say it's the [supplier] people, the [supplier] people say it's the [local service provider] people, [local service provider] people say it's your trust. Actually, it makes things a bit difficult because people are passing the buck a bit."-_doctor, site $\mathrm{M}$. 
"[Local service providers], with the best will in the world, are only ever going to fulfil the contract; they're in business. They are, in some areas, beginning to kind of loosen up and understand that, actually, the success is only going to follow a much more integrated style of working with the NHS."IT staff, site B.

With contracts structured such that local service providers are paid after deployment of applications to hospital trusts, delays in rollout also had a major impact on local service provider finances. Local service providers described their contracts as "punitive" and driving the wrong behaviours - the second point was also endorsed by some trust staff.

"We have to move out of that culture of responding to national pressure or the Parliamentary Accounts Committee setting six month targets because that drives all the wrong behaviour. We have to be more outcome driven rather than, you know, date and milestone driven."-local service provider B, interviewee 2.

"I don't know how the contracts are written ... but what it looks like from a ground-upwards perspective is that it's written in such a way that [local service provider] don't actually have to worry about the quality they're delivering and whether it actually works; they just, all they have to do is to just basically just get bodies on the floor."-IT manager, site $\mathrm{H}$.

Planned deployment schedules were widely viewed as politically and contractually driven and described by some interviewees as "unrealistic" and as "ludicrous" from the outset. Premature deployments had negative consequences for users' perceptions of local service provider solutions, for instance, where the technology itself was not deemed ready by users (such as "clunky," slow to use, unreliable, with minimal clinical functionality) or where there were publicised reports of trusts struggling with adverse consequences after deployment or upgrade of an NHS Care Records Service system.

“... to me it's a very immature product ... they need to take it away for six months and work with some clinicians and then bring it back."-manager, site C. "The issues at [hospital trust] were very big, and I think what tends to happen is, it's not the reality ever that counts, sadly, it's people's perceptions, and the perception by clinicians is that it's all [the application's] fault."-implementation team, site A.

Local service providers' solutions were also viewed by users as technologically unsophisticated, in some cases less good than the healthcare IT systems they had replaced.

"It's a disappointment to have a clinical tool that is not as advanced as what I can do when I go and do my internet shopping for my weekly shop."clinician, site $\mathrm{M}$.

"I think the information system that we had before was possibly better."-clinician 2, site M.
Furthermore, specifications written into long term contracts did not keep pace with technological advances.

"The current log-on method that people have is these 'smartcards.' It's like antiquated technology. It's a card that goes in a hole. What infection risk is that, for starters? ... I mean, it should be something that's proximity, wireless."-local service provider $\mathrm{B}$, interviewee 2 .

Trusts want systems that are tailored to their particular organisation, not standardised systems

Trusts wanted greater control over the NHS Care Records Service; they had strongly perceived needs for the standard solutions to be tailored to individual NHS trusts, which saw themselves as diverse and complex organisations. NHS interviewees sought systems that were quickly responsive to changing central and local NHS priorities, hence able to support a trust's business requirements, capable of local adaptation to suit individual trust's varied processes and work practices, quick and reliable for staff to use, and offering early clear benefit to clinicians.

"I understand they're trying to put in a national product, but I think, you know, at the end of the day, does one size fit all? I'm afraid it doesn't." administration director, site $\mathrm{H}$.

Local service providers acknowledged difficulties from the outset arising from trying to implement inflexible standardised applications.

"It was set up almost guaranteed to run into the problems that have subsequently been experienced in that the standardised model as conceived by the centre was not what the end users were looking for."-local service provider B, interviewee 1 .

"So it's just disconnected ... Obviously we need the NHS to tell us what the priorities are. And I think if we remain in a place where Connecting for Health tell us what those priorities are, we're always going to be disconnected."-local service provider B, interviewee 2 .

Locally configuring the local service provider solutions could cost substantially more than deploying standard local service provider applications in each trust $-50 \%$ more per deployment according to one interviewee (local service provider A, interviewee 1). The extent to which the need for local tailoring was more perceived than real was questioned by another local service provider interviewee (formerly an NHS clinician), who suggested the primary need was for NHS organisations to agree on greater standardisation of clinical practices.

"If you have what I call a customer focus, turn it on its head and do it correctly for the patient, and standardise on clinical practice, the rest should follow."-local service provider A, interviewee 2 .

Low levels of IT skills in NHS trusts, trusts' lack of resources for IT infrastructure and for staff training, and, more widely, a perceived lack of fundamental understanding that the aim of the National Programme 
for IT is to transform healthcare organisation and care delivery were also highlighted by a diverse range of interviewees as important barriers to deployment of electronic health records.

Community level approaches to deployment of electronic health records and data sharing may be the optimal way forward

Focusing on the successful sharing of detailed electronic health records at the smaller-scale level of naturally occurring, local health communities was widely perceived to offer the "biggest bang for buck" (local service provider $\mathrm{A}$, interviewee 1). A local health community would not conform to a specified geographical area, rather it might consist of one or more, neighbouring hospital trusts with primary care providers and associated local community, pharmacy, and mental health services.

"More than $90 \%$ of health care is delivered within that thing [local health community]. Now, of course, people get referred out to [specialist children's hospital] from wherever, but that's actually relatively rare."-local service provider A, interviewee 1 .

In England, hospitals' services are commissioned by primary care trusts. NHS interviewees thus often perceived neighbouring hospital trusts to be local rivals that competed for business, yet there were also suggestions for future cooperation and resource sharing between NHS organisations implementing the same NHS Care Records Service application, for instance, by placing staff in each others' trusts.

"What would be useful would be for some of our guys, yeah, basically to do role swaps. I mean, in an ideal world that's what you'd want to do, you'd want to be able to send some of your staff-whether they be doctors, nurses, physios, porters, whoeverto do role swaps."-implementation manager, site A.

"So I think one of the lessons the NHS has to learn is it needs to drive an economy of scale through bringing together of existing capabilities within organisations into a bigger, shared service across those organisations."-IT staff, site B.

The need for leadership to realise community level cooperation was highlighted.

"I think we have a problem because there's a lack of trust between the trusts, so there seems to be a lot of suspicion because of the new arrangements with the sort of commissioning provider stuff. I think there's a little bit of, what's the word, distrust, you know ... If there was better leadership it would work well, but at the moment we're kind of treading water, you know, sinking, because the leadership is not there, which is disappointing."-IT staff, site $\mathrm{H}$.

For some London interviewees, including NHS staff, the proposed model of cooperation between trusts reflected prior, personal experience of such resource sharing when, before the National Programme for IT started, three local NHS trusts had cooperated to deploy the same IT system sequentially in their organisations.

"For the first deployment, the final two trusts had staff project managers and staff working in the first, and then the first helped out the second, and then the third. In 18 months we achieved what it now takes about five years to do, because of that process."-local service provider A, interviewee 2 .

\section{DISCUSSION}

\section{Summary of main findings}

These interim findings show that the initial, top-down policy of standardised NHS Care Records Service applications in secondary care in England has, for a range of reasons, had to evolve into an approach that is more responsive to the circumstances and expressed wishes of individual hospital trusts. Although the original plan has faltered, foundations for detailed electronic health records are emerging as the approach continues to adapt to permit more local choice and as NHS staff and other stakeholders gain greater insight into both the risks and promise of electronic health records. Deployment delays to date were often attributed to an unrealistic, politically driven timeline from the outset. Multiple tensions between a central programme and the local NHS "customers," convoluted communication lines, and NHS trusts' lack of capacity and readiness for IT enabled change all contributed to delays.

The future of the National Programme for IT is still uncertain in light of the new coalition government taking office and forthcoming cuts in public spending. Some fear that policy makers might now swing from the initial top-down approach to the opposite, a bottom-up approach, whereas the more desirable approach suggested by several interviewees is a hybrid of the two, recognising a place for both central and local responsibilities and with efforts at sharing detailed electronic health records focused on local health communities. Our interviewees' accounts are concordant with the fundamentally socio-technical character of electronic health records and the need to allow the mutual alignment of the technology and the people who work with it. ${ }^{3536}$

\section{Strengths and limitations of this work}

We are evaluating a phenomenon that is still unfolding, and the prospective, longitudinal design should allow us to discriminate between transitory and more sustained consequences of implementation and adoption of electronic health records. Accessing a wide range of stakeholder perspectives and multiple data sources illuminates changing, multifaceted, socio-technical processes - and is strengthened by purposive sampling of early adopter sites and theoretically informed data collection and analysis. Previous qualitative work has focused on a single group of senior NHS professionals, ${ }^{10}$ whereas we are accessing the views and experiences of many groups inside and outside the case study trusts, including, importantly, the users 
of the new systems. The comprehensive approach should enhance the transferability of our findings and conclusions.

Data collection, coding, and analysis at each case study site were primarily carried out by a single researcher, which allowed the lead researcher to develop familiarisation with that site and a rich understanding of its dataset. This approach, combined with transparency and checking at each stage of data collection, coding, and analysis with the wider research team and beyond, ensured findings were grounded in the data.

We were unable to access confidential local service provider contracts. Partly as a result of this, it has proved challenging to gain a holistic understanding of the overall National Programme for IT. Other bodies reviewing the programme, such as the House of Commons Public Accounts Committee have experienced similar challenges in accessing sensitive commercial information. ${ }^{2632}$

Our interim findings are based on the first round of data collection from five sites at the forefront of implementation efforts, sampling diverse NHS organisations and all three hospital applications of the NHS Care Records Service. When data collection and analysis are complete, we will be able to compare longitudinal experiences of implementing these applications in a wider range of local contexts, reporting from 11 secondary care settings. Preliminary data from the additional six sites, not yet reported, strongly support our key interim themes, suggesting high transferability to other early adopter sites. Early adopters may differ in important ways from NHS trusts that will join the NHS Care Records Service programme later or not at all. While the five trusts reported here are likely to be representative of early adopters, we acknowledge they may not be representative of all secondary care trusts in England.

More generally, the optimal timing for publishing results of policy-focused evaluations must strike a balance between providing early formative feedback that can usefully shape policy development and providing later feedback that is strengthened by increased evidence but is reported too late to influence policy direction. Our evaluation is likely to end before new applications and new ways of working have reached stability, at which time further positive and negative consequences of electronic health records may emerge.

\section{Considering these findings in an international context}

The current literature is dominated by reports of single organisations' implementations of, often home-grown, electronic health records, ${ }^{37}$ but countries such as the United States and Australia are now embarking on nationwide initiatives. ${ }^{38} 39$ Such nationwide health information and communication initiatives and their consequences-particularly with respect to data exchange-are new terrain. ${ }^{340}$ England, the United States, and Australia are starting with quite different health services. They are also taking different approaches to achieving nationwide electronic health records, which have been categorised as "bottom-up" (US), "middle-out" (Australia), and "top-down" (England). ${ }^{41}$

A bottom-up approach might preserve existing local systems and exploit the emergence of interoperability standards in order to exchange healthcare information and support the patient journey. In contrast, a topdown approach is centrally directed and replaces existing, diverse local systems with the aim of creating and storing a single, sharable electronic health record. A middle-out approach combines central support for national goals and common standards with incentives to encourage incremental compliance with standards at the local level.$^{41}$ The US government offers financial incentives for "meaningful use" of accredited systems, and regional data exchanges are planned. ${ }^{4243}$ Hence, local level choice is more constrained than the term "bottom-up" might suggest. In England, the partial migration from a top-down approach towards a middle-out approach reflects the interplay of dynamic and complex interactions in the course of the National Programme for IT. Arguably, both the US and the English approach are now more closely aligned with each other and with that of Australia, all as variations of a "middleout" approach. A major uncertainty remains about how well these approaches will achieve meaningful data exchange that supports patient care, which will in part depend on the balance between local level freedoms and constraints.

\section{Policy implications}

Major policy revisions affecting the National Programme for IT are anticipated after the recent election of a new coalition government and announcements of widespread cuts to public spending to address the UK national deficit. Even small policy adjustments that are based on early evidence from evaluations can substantially influence developments in a programme as large, complex, and ambitious as introducing nationwide electronic health records. For example, interim results from the evaluation of the summary care record are believed to have played an important role in influencing revisions to the consent model. ${ }^{8}$

The health service in England is made up of a variety of diverse NHS organisations, some with considerable autonomy as NHS foundation trusts. There is also a degree of competition between local hospital trusts that tender to provide services to primary care commissioners. Our data highlight an inherent tension between government policies that have encouraged decentralisation of NHS control ${ }^{44}$ and a policy to supply centrally procured, standardised IT systems to local NHS settings. A further policy tension was evident in writing systems requirements into long term contracts for NHS IT applications while national directives for service delivery and reporting by NHS trusts continually change. Similarly, technologies change, which can quickly result in long term contracts becoming technologically outdated. 


\section{WHAT WAS ALREADY KNOWN ON THIS TOPIC}

In England the government launched a national programme to implement centrally procured, standardised, detailed electronic health record systems throughout all 168 acute hospital and 73 mental health trusts by 2010

This programme is considerably behind schedule

\section{WHAT THIS STUDY ADDS}

Interim results from the first, comprehensive, prospective, longitudinal evaluation of implementing and adopting nationwide electronic health records in secondary care indicate that a top-down, centrally driven policy to deliver standardised records systems to diverse local NHS organisations has contributed to deployment delays and frustrations

The top-down approach has had to evolve to permit greater flexibility and local choice in electronic health record systems and their delivery

A realistic timescale for achieving detailed electronic health records in secondary care must recognise that it is an incremental and iterative process, requiring active engagement from clinicians and managers, and it is likely to take many years to deliver all its potential benefits

The immediate priority is to clarify the type and scale of detailed electronic health records that are wanted and affordable tensions and programme changes. Considering nationwide implementations of electronic health records with the aid of broad categories such as a "middleout" versus a "top-down" approach is useful but limited. In England, debates about other important dimensions - such as what kind of detailed electronic health record is wanted, on what scale, and how much the country is prepared to pay for it - are still far from settled. Our fourth recommendation, therefore, is that clearly answering these more fundamental questions should be policy makers' first priority.

\section{Conclusions}

The English experience indicates that a "vision" of introducing nationwide electronic health records in the context of a broader aim to improve national health care can successfully kick-start an ambitious programme of IT based transformation. Realising the vision, however, is likely to be an incremental and iterative process that unfolds over many years. Such a timescale emphasises the need for flexibility and local adaptability, both in the electronic health record systems and in how they are delivered to accommodate technological developments and changing local and national priorities. Public debates pitting centrally driven, standardised systems versus common standards and interoperability might more usefully be reframed as a debate about exactly what kind of a nationwide electronic health record is now needed and affordable. While there is no clear evidence as yet that a middleout approach will achieve the goal of large scale nationwide electronic health records, international experience, including England's, suggests that neither a purely top-down nor bottom-up approach is likely to do so.

We thank the participating trusts for supporting this work and all interviewees who kindly gave of their time. We are grateful to the Independent Project Steering Committee overseeing this evaluation (chaired by Professor David Bates and including Professor Martin Buxton, Antony Chuter, Lee Priest, and Kathy Mason). We also thank the independent NHS Connecting for Health Evaluation Programme (CFHEP), led by Professor Richard Lilford and supported by Jo Foster and Lee Priest from the University of Birmingham. We thank Professors Denis Protti, Trish Greenhalgh, and David Bates for constructive comments on an earlier draft of this manuscript.

Contributors: AS conceived this study and — with KC, BF, RP, AA, AJ, TC, EK, JP, and NB-secured the funding for this work. They, together with CQ and JW, are the grant holders for this project. AS is the overall principal investigator, with AA, TC, and NB leading research from their respective centres. KC, AT, DP, SC, VL, MA, ZM, YJ, KM, and AR are the researchers working on this evaluation. AR and AS led the writing of this manuscript with co-authors commenting on drafts of the paper. AR and AS are guarantors for the study.

Funding: This report is independent research commissioned by the National Institute for Health Research. The views expressed in this publication are those of the authors and not necessarily those of the NHS, the National Institute for Health Research, or the Department of Health. Competing interests: All authors have completed the Unified Competing Interest form at www.icmje.orge/coi_disclosure.pdf (available on request from the corresponding author) and declare that (1) all authors have support in the form of a grant from the NHS CFHEP for the submitted work; (2) no author has a relationship with any company that might have an interest in the submitted work in the previous three years; (3) no author's spouse, partner, or children have financial relationships that may be relevant to the submitted work; and (4) no author has non-financial interests that may be relevant to the submitted work. 
Data sharing: Additional supporting data drawn from the five, interim case studies reported here are available on request from the corresponding author (aziz.sheikh@ed.ac.uk).

1 Catwell L, Sheikh A. Evaluating ehealth interventions: the need for continuous systematic evaluation. PLoS Med 2009;6:e1000126.

2 Protti D. Comparison of information technology in general practice in 10 countries. Healthcare Q 2007;10:107-15.

3 Car J, Black A, Anandan C, Cresswell K, Pagliari C, McKinstry B, et al. The impact of ehealth on the quality and safety of healthcare. $a$ systematic overview and synthesis of the literature. 2008. www.haps. bham.ac.uk/publichealth/cfhep/documents/NHS_CFHEP_ 001_Final_Report.pdf.

4 Jha AK, DesRoches CM, Campbell EG, Donelan K, Rao SR, Ferris TG, et al. Use of electronic health records in US hospitals. N Engl / Med 2009;360:1628-38.

5 National Audit Office. The National Programme for IT in the NHS: progress since 2006. NAO, 2008. www.nao.org.uk/ publications/0708/the_national_programme_for_it.aspx.

6 Department of Health. Delivering 21st century IT support for the NHS national strategic programme. DoH, 2002. www.dh.gov.uk/en/ Publicationsandstatistics/Publications/PublicationsPolicyAnd Guidance/DH 4008227.

7 NHS Connecting for Health. NHS Care Records Service (NHS CRS). 2010. www.connectingforhealth.nhs.uk/systemsandservices/scr/ intro/nhscrs/index html.

8 Greenhalgh T, Stramer K, Bratan T, Byrne E, Mohammad Y, Russell J. Introduction of shared electronic records: multi-site case study using diffusion of innovation theory. BMJ 2008;337:a1786.

9 Greenhalgh T, Stramer K, Bratan T, Byrne E, Russell J, Potts HW. Adoption and non-adoption of a shared electronic summary record in England: a mixed-method case study. BMJ 2010;340:c3111.

10 Hendy J, Fulop N, Reeves BC, Hutchings A, Collin S. Implementing the NHS information technology programme: qualitative study of progress in acute trusts. BMJ 2007;334:1360.

11 Department of Health. Equity and excellence: liberating the NHS. Stationery Office, 2010.www.dh.gov.uk/prod_consum_dh/groups/ dh_digitalassets/@dh/@en/@ps/documents/digitalasset/ dh_117352.pdf.

12 Murray SA, Sheikh A. Serial interviews for patients with progressive diseases. Lancet 2006;368:901-2.

13 Cornford T, Doukidis GI, Forster D. Experience with a structure, process and outcome framework for evaluating an information system. Omega, International Journal of Management Science 1994;22:491-504.

14 Patton MQ. Qualitative evaluation and research methods. 2nd ed. Sage Publications, 1990

15 Mays N, Pope C. Quality in qualitative health research. In: Qualitative research in health care. 1st ed. BMJ Publication Group, 1999.

16 Corbin J, Strauss A. Strategies for qualitative data analysis. In: Basics of qualitative research. Techniques and procedures for developing grounded theory. 3rd ed. Sage Publications, 2008.

17 Silverman D. Doing qualitative research: a practical handbook. Sage, 2000

18 Coiera E. Four rules for the reinvention of health care. $B M J$ 2004;328:1197-9.

19 Malterud K. Qualitative research: standards, challenges and guidelines. Lancet 2001;358:483-8.

20 Cresswell K, Sheikh A. The NHS Care Record Service: recommendations from the literature on successful implementation and adoption. Inform Prim Care 2009;17:153-64.

21 NHS Executive. Information for Health: an information strategy for the modern NHS 1998-2005. Department of Health, 1998. www.dh.gov.uk/ prod_consum_dh/groups/dh_digitalassets/@dh/@en/ documents/digitalasset/dh_4014469.pdf.

22 House of Commons Library. NHS funding and reform: the Wanless Report. 2002. www.parliament.uk/commons/lib/research/rp2002/ rp02-030.pdf
23 Royal Academy of Engineering, British Computer Society. The challenges of complex IT projects. Royal Academy of Engineering, 2004. www.raeng.org.uk/news/publications/list/reports/ Complex_IT_Projects.pdf

24 British Computer Society. The way forward for NHS health informatics. BCS,

2006. www.bcs.org/upload/pdf/BCS-HIF-report.pdf

25 National Audit Office. Department of Health: The National Programme for IT in the NHS. NAO, 2006. www.nao.org.uk/publications/ 0506/department_of_health_the_nati.aspx

26 House of Commons Committee of Public Accounts. Department of Health: The National Programme for IT in the NHS. Twentieth Report of Session 2006-07. Stationery Office, 2007. www.publications. parliament.uk/pa/cm200607/cmselect/cmpubacc/390/390.pdf.

27 Department of Health. High quality care for all: NHS Next Stage Review final report. Stationery Office, 2008. www.dh.gov.uk/ prod_consum_dh/groups/dh_digitalassets/@dh/@en/ documents/digitalasset/dh_085828.pdf

28 Department of Health. Health informatics review: report. Stationery Office, 2008. www.dh.gov.uk/prod_consum_dh/groups/dh_ digitalassets/@dh/@en/documents/digitalasset/dh_086127.pdf

29 Royal College of General Practitioners. Informing shared clinical care Final report of the shared record professional guidance project. RCGP, 2009. www.rcgp.org.uk/pdf/Get_Involved_SRPG_final_ report.pdf

30 Joseph Rowntree Reform Trust. Database state. Joseph Rowntree Reform Trust, 2009. www.jrtt.org.uk/uploads/Database $\% 20$ State.pdf

31 Independent review of NHS and social care IT. 2009. www. stephenobrien.org.uk/pdf/THE\%2ONHS\%2OAND\%20SOCIAL\% 20CARE\%20IT\%2OREVIEW\%202009.pdf

32 House of Commons Public Accounts Committee. The National Programme for IT in the NHS: progress since 2006. Stationery Office, 2009. www.publications.parliament.uk/pa/cm200809/cmselect/ cmpubacc/153/153.pdf.

33 Cruickshank J. Fixing NHS IT: A plan of action for a new government. 2020health, 2010. www.2020health.org/export/sites/2020/pdf/ 2020itdocA4MASTERlow27-04.pdf

34 Monitor. Independant Regulator of NHS Foundation Trusts. www. monitor-nhsft.gov.uk/home.

35 Catwell L, Sheikh A. Information technology (IT) system users must be allowed to decide on the future direction of major national IT initiatives. But the task of redistributing power equally amongst stakeholders will not be an easy one. Inform Prim Care 2009;17:1-4

36 Peltu M, Eason K, Clegg C. How a socio-technical approach can help NPfIT deliver better NHS care. 2008. www.bcs.org/upload/pdf/ sociotechnical-approach-npfit.pdf.

37 Chaudhry B, Wang J, Wu S, Maglione M, Mojica W, Roth E, et al. Systematic review: impact of health information technology on quality, efficiency and costs of medical care. Ann Intern Med 2006;144:742-52.

38 The White House. Health care. Health reform. www.whitehouse.gov issues/health-care.

39 National eHealth Transition Authority. www.nehta.gov.au/ coordinated-care.

40 Schiff GD, Bates DW. Can electronic clinical documentation help prevent diagnostic errors? N Engl / Med 2010:362;1066-9.

41 Coiera E. Building a national health IT system from the middle out.) Am Med Inform Assoc 2009;6:271-3.

42 United States Congress. American Recovery and Reinvestment Act of 2009/Division B/Title IV Health Information Technology for Economic and Clinical Health Act. http://en.wikisource.org/wiki/ American_Recovery_and_Reinvestment_Act_of_2009/Division_B/ Title_IV.

43 Blumenthal D. Stimulating the adoption of health information technology. N Engl J Med 2009;360:1477-9.

44 Harrison M. Implementing change in health systems. Sage Publications, 2004.

Accepted: 5 August 2010 